\title{
INVESTIGATIONS INTO SUCCINIC ACID FERMENTATION
}

\author{
ÁRON NÉMETH *1 \\ ${ }^{1}$ Department of Applied Biotechnology and Food Science, Budapest University of Technology and \\ Economics, Müegyetem rkp. 3, Budapest, 1111, HUNGARY
}

\begin{abstract}
Succinic acid (SA) is an important chemical intermediate from which fine chemicals ( e.g. detergents), additives (for pharmaceuticals, food (taste), plant growth stimulants) as well as other important intermediates (maleic anhydride, succinimide, 2-pyrrolidinone, dimethyl succinate) can be manufactured. Since SA is involved in the central metabolism of cells (in the tricarboxylic acid (TCA) cycle), it is a key player in the biochemistry of life, which has the potential of biotechnological production. Since SA is formed in the "middle" of the TCA cycle it can be formed by both $\mathrm{CO}_{2}$ production and fixation. The significance of the latter is that the amount of the product can be controlled by the availability of $\mathrm{CO}_{2}$, since stoichiometrically one molecule of $\mathrm{CO}_{2}$ is fixed by one molecule of SA. In our studies of compositions of Actinobacillus succinogenes media, the role and effect of $\mathrm{pH}$ regulator compounds as well as the effect of an inert atmosphere were investigated in terms of the yield. Furthermore, in fermentation experiments, the application of higher sugar concentrations was also studied. On the basis of different fermentations, a neural network for modelling and describing how factors influence SA production was established.
\end{abstract}

Keywords: succinic acid, Actinobacillus succinogenes, neural network, modelling

\section{Introduction}

Succinic acid (SA), as an intermediate of the tricarboxylic acid (TCA) cycle, plays an essential role in the metabolism of microorganisms. SA can be produced by many anaerobes or facultative anaerobes as a metabolic product, thus can be used as an important platform chemical, a precursor of many pharmaceuticals, feed additives, green solvents or biodegradable polymers. SA itself is a colourless, odourless and crystal-forming compound. Since this metabolite is bifunctional $\left(\mathrm{pK}_{a_{1}}=4.21\right.$, $\mathrm{pK}_{a_{2}}=5.72$ [1]), it is very reactive so has many potential applications, e.g. it plays important roles in the synthesis of $\gamma$-butyrolactone, maleic anhydryde, succinimide, 1,4butanediol, dimethyl succinate, succinonitrile and 1,4diaminobutane. It is industrially produced, mainly synthetically, in a complex way from maleic anhydride found in crude oil, which is both economically and environmentally unfavourable [2]. Therefore, its biotechnological production is a current research topic to find an alternative method to avoid the above-mentioned side effects [3]. Furthermore, a great advantage of the microbial production of SA is that one of the initial biochemical reactions is the carboxylation of phosphoenolpyruvate [4] which is regulated in the case of anaerobic bacteria by the availability of $\mathrm{CO}_{2}$ [2], thus the elevation of the $\mathrm{CO}_{2}$ concentration can shift product portfolio from formate and ethanol towards SA (Fig. 1).

\footnotetext{
*Correspondence: naron@f-labor.mkt.bme.hu
}

Despite this fact, the process can help to decrease the $\mathrm{CO}_{2}$ emissions of the human population [5]. Both fungi and bacteria can be found among the SAproducing microorganisms, but their ability to produce SA differs significantly: fungi $\sim 45 \mathrm{~g} / \mathrm{L}$ (Aspergillus niger, rec. Yarrowia lipolytica), Gram-negative bacteria (wild-type Actinobacillus succinogenes $98.7 \mathrm{~g} / \mathrm{L}$, Mannheimia succiniciproducens $90 \mathrm{~g} / \mathrm{L}$ ) and Grampositive bacteria (Clostridium thermosuccinogenes 82.5 $\mathrm{g} / \mathrm{L}$, rec. Corynebacterium glutamicum $145 \mathrm{~g} / \mathrm{L}$ ) [5]. The most frequently applied strains in the industry are Aspergillus niger, Aspergillus fumigatus, Byssochlamys nivea, Lentinus degener, Paecilomyces variotii, Penicillium viniferum, Saccharomyces cerevisiae and Actinobacillus succinogenes [4].

The latter bacterium is one of the most prominent producer strains that is isolated from bovine rumen and has been identified as a member of the genus Pasteurella, which is a facultative anaerobic, non-motile, Gram-negative pleomorphic, rod-shaped bacterium [2]. It has great potential in terms of SA production, because of its higher yield and wide range of applicable substrates, e.g. glucose, cellobiose, maltose, lactose, saccharose, fructose and sorbitol. Furthermore, it can tolerate high initial concentrations of glucose, therefore, is suitable for simple batch fermentation instead of the more complex and costly fed-batch culture technique [5]. The most widely applied strains are Actinobacillus succino- 


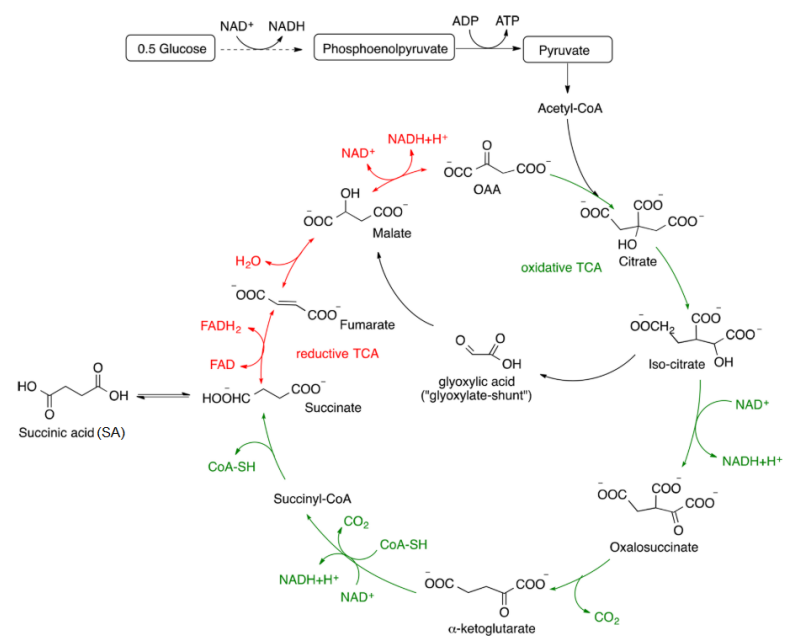

Figure 1: $\mathrm{SA}$ metabolism with $\mathrm{CO}_{2}$ regulation

genes $130 \mathrm{Z}$ and its variants (FZ6, 9, 21, 45 and 53) [2], which can tolerate both high glucose and SA concentrations as well as achieve high SA yields [5].

The aim of this paper is to compare fermentations of Actinobacillus succinogenes under different experimental conditions, then - due to the many influential factors - to set up a neural network-based model which can be used to predict high SA titres.

\section{Materials and Methods}

\subsection{Cultivation of the bacteria}

Actinobacillus succinogenes 130Z (DSM22257) was cultivated in $10 \mathrm{ml}$ of tryptic soy broth (TSB) (Sigma) in an impedimetric BacTrac 4100 (SY-LAB, Austria) anaerobic cell. For a $1 \mathrm{~L}$ fermentation with a working volume of $0.8 \mathrm{~L}$, an AS medium was applied according to Liu et al. [5] as follows: $62.5 \mathrm{~g} / \mathrm{L}$ total sugar including 44.9 $\mathrm{g} / \mathrm{L}$ saccharose, $9.8 \mathrm{~g} / \mathrm{L}$ glucose and $7.2 \mathrm{~g} / \mathrm{L}$ fructose supplemented with $15 \mathrm{~g} / \mathrm{L}$ yeast extract, $1.5 \mathrm{~g} / \mathrm{L} \mathrm{NaHPO}_{4}$, $1 \mathrm{~g} / \mathrm{L} \mathrm{Na}_{2} \mathrm{HPO}_{4}, 1 \mathrm{~g} / \mathrm{L} \mathrm{NaCl}, 0.2 \mathrm{~g} / \mathrm{L} \mathrm{MgCl} 2$ and $0.2 \mathrm{~g} / \mathrm{L}$ $\mathrm{CaCl}_{2}$. During preliminary tests, a temperature of $37^{\circ} \mathrm{C}$ was not successful for SA production, therefore, $34^{\circ} \mathrm{C}$ was applied and the $\mathrm{pH}$ regulated by $3 \mathrm{M} \mathrm{Na}_{2} \mathrm{CO}_{3}$. After each fermentation, $200 \mathrm{ml}$ of broth remained in the reactor and $600 \mathrm{ml}$ was extracted, while $600 \mathrm{ml}$ of fresh AS media was introduced. The 5 different fermentations are compared in the Results section.

An innovative solution was to apply a $\mathrm{CO}_{2}$ economical gas supply through the oxygen enrichment system of a Biostat Q DCU3 fermentor system in the absence of air and oxygen. The gas mix oxygen enrichment regulator was set at $4 \%$, therefore, periodically a small amount of $\mathrm{CO}_{2}$ was introduced into the fermentation broth.

\subsection{Analysis}

During fermentations, samples were taken periodically and the optical density (OD) determined by a spectropho- tometer (Ultrospec Plus, Pharmacia LKB) at a wavelength of $600 \mathrm{~nm}$ (OD600) against the supernatant of a centrifuged sample by applying the same dilution factor $(5 \times)$ as in the case of the samples. The cell dry weight (CDW) was obtained by a multiplication factor of 2 from OD600. Substrate consumption and product as well as by-product formation were detected by the Waters Breeze

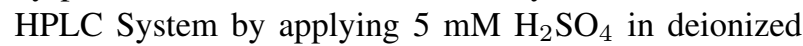
water at a flow rate of $0.5 \mathrm{ml} / \mathrm{min}$ through a BioRad Aminex HPX87H column at $65^{\circ} \mathrm{C}$ in a refractive index (RI) detector at $40^{\circ} \mathrm{C}$.

\subsection{Neural networking}

For model building and evaluation, Neural Designer $v 2.9 .5$ was used by applying the following 4 steps:

1. Fermentation data were combined into a single MS Excel spreadsheet and exported to a tab-delimited text file, which could be imported into the modelling software. 9 variables, i.e. 7 inputs (time, lactic acid, acetic acid, propionic acid, glycerol, ethanol, total sugar) and 2 outputs (succinic acid, CDW), were applied to 58 fermentation samples from which 36 were used for training the network, 11 were selected and 11 were used for testing the behaviour of the model.

2. From among the many options, a model was defined (Fig. 2) by automatic scaling, without any principle component, with 2 layers and 3 neurons/hidden layers that exhibit a logistic activation function in the absence of a bounding layer. In terms of a training strategy, the normalized mean squared error method was selected using a Quasi-Newton algorithm and a maximum of 1000 iterations. Incremental order was chosen as the order selection algorithm together with the growing inputs.

3. Model fit, i.e. performance training, was conducted.

4. Output of the model: impact figures of factors were determined (the other parameters were fixed), model equations obtained and predictions made by implementing input data into an input data matrix.

\section{Results and Discussion}

Since Actinobacillus succinogenes is a facultative anaerobic microorganism, the first fermentation experiment (Fig. 3A) was started in the absence of any specific atmosphere.

However, it ran very slowly, therefore, around $48 \mathrm{~h}$ (denoted by a red arrow) of continuous $5 \% \mathrm{CO}_{2}$ enrichment was applied via a zero flow rate gas inlet. The experiment confirmed that the application of $\mathrm{CO}_{2}$ is essential to form SA, therefore, finally $6 \mathrm{~g} / \mathrm{L} \mathrm{SA}$ was achieved and the model fitted very well for both CDW and SA measurements. 


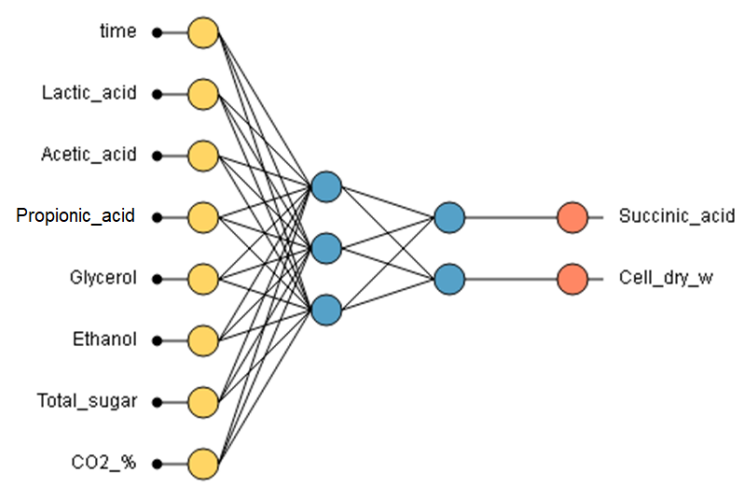

Figure 2: The used neural network for describing SA fermentations

Therefore, the next fermentation (Fig. 3B) was conducted under $5 \% \mathrm{CO}_{2}$ enrichment of zero flow rate gas inlet and resulted in the highest $16 \mathrm{~g} / \mathrm{L} \mathrm{SA}$ (besides 11 $\mathrm{g} / \mathrm{L}$ residual sugar) corresponding to a yield of $37 \%$. To increase the economic feasibility, the amount of $\mathrm{CO}_{2}$ was reduced by $50 \%$ to $2.5 \%$ in the following experiment (Fig. 3C). To avoid a fall in the SA concentration, detected by-products (such as lactic acid $3.5 \mathrm{~g} / \mathrm{L}$, acetic acid $5.7 \mathrm{~g} / \mathrm{L}$, propionic acid $1.7 \mathrm{~g} / \mathrm{L}$ and glycerol $1.3 \mathrm{~g} / \mathrm{L}$ ) should be repelled as a result of the addition of $20 \mathrm{~g} / \mathrm{L}$ calcium lactate.

The model once again fitted well to the measured CDW and SA values. Unfortunately, the carbon flux shifted towards propionic acid formation, therefore, the subsequent experiment (Fig. 3D) was both supplemented with $20 \mathrm{~g} / \mathrm{L}$ lactic acid and $11 \mathrm{~g} / \mathrm{L}$ propionic acid, but this resulted in a low level of SA and a high level of lactic acid $(52 \mathrm{~g} / \mathrm{L})$. The model yet again fitted well to the measured CSW and SA values.

Independent fermentation results were also checked by the model (Fig. 3E) and resulted in very good fits. It can be concluded that the artificial neural network model constructed described well the SA fermentations, which is in line with the results of Li et al. [7], namely that artificial neural network models can describe succinic acid fermentation better than response surface methodology.

The presented results revealed that for SA fermentation, $5 \% \mathrm{CO}_{2}$ enrichment is essential and cannot be fully or partially replaced with the addition of lactic acid or propionic acid.

After validating the model by conducting 5 different fermentations, it was used to optimize influential factors via impact figures (directional output plots) (Fig. 4).

These trends show that all the presented factors correlate with SA concentration, i.e. any increment in their amounts resulted in an increment in SA, with the exception of propionic acid which exhibited a negative correlation. These suggest that the addition of propionic acid can decrease the concentration of SA obtained and the addition of lactic acid can increase it.

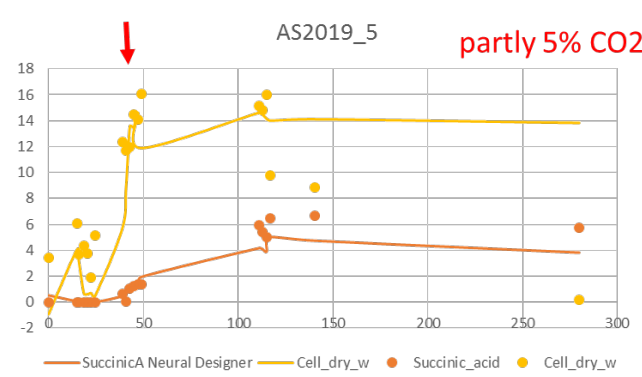

(A)

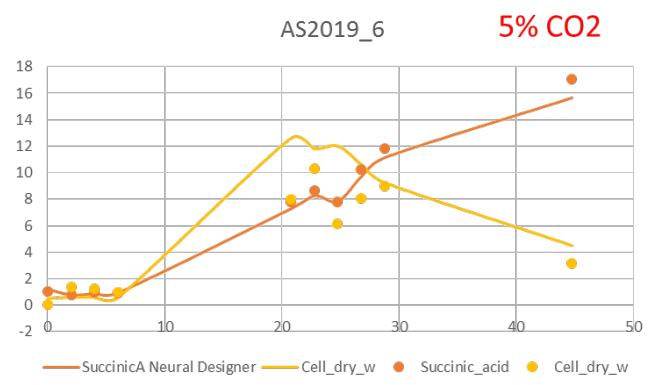

(B)

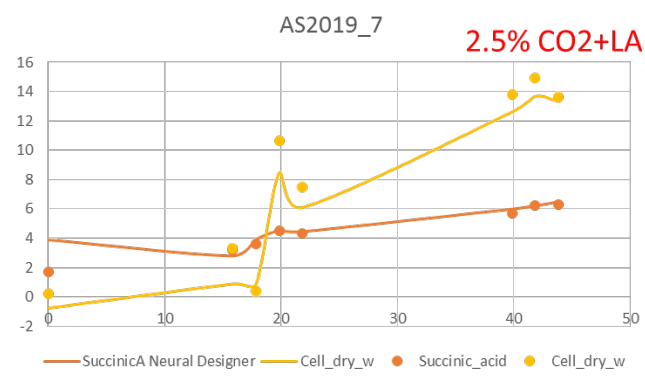

(C)

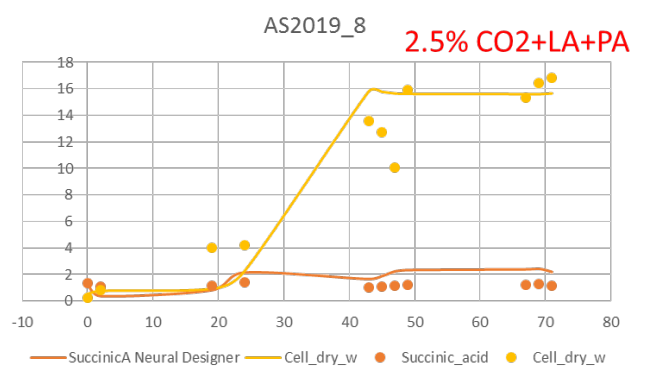

(D)

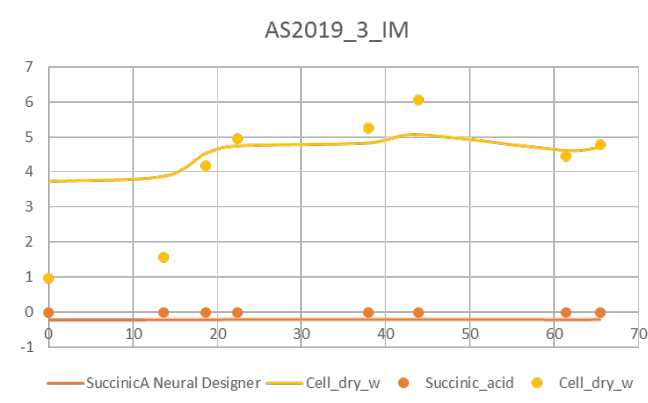

(E)

Figure 3: Actinobacillus succinogenes fermentations with different degrees of $\mathrm{CO}_{2}$ enrichment in combination with lactic acid (LA) and propionic acid (PA). Dots indicate the measured values and lines indicate the model prediction. 


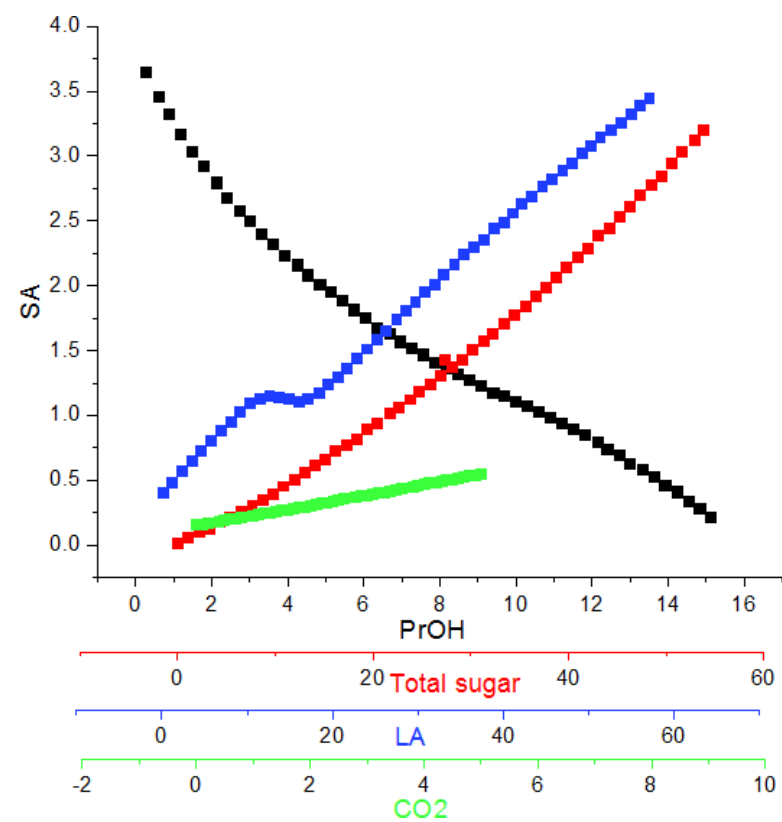

Figure 4: Factors impact plots: $\mathrm{PrOH}$ - propionic acid $(\mathrm{g} / \mathrm{L})$, Total sugar $(\mathrm{g} / \mathrm{L}), \mathrm{LA}-$ lactic acid $(\mathrm{g} / \mathrm{L})$ and $\mathrm{CO}_{2}-$ carbon dioxide $(\%)$

\section{Conclusion}

Five Actinobacillus succinogenes fermentations were run under different conditions: semi-anaerobic method, controlled introduction of $\mathrm{CO}_{2}$, and introduction of $\mathrm{CO}_{2}$ combined with either the addition of lactic acid or both lactic acid and propionic acid. All together 58 samples were taken and analysed, the results of which were entered into Neural Designer modelling software and used for training and testing the model. While the fermentations resulted in very different final SA concentrations, the established model fitted well to all of the fermentations, even to the one which was not used for model building, testing and validation. While economical $\mathrm{CO}_{2}$ enrichment was successfully applied and resulted in the highest SA yield (37\%), the addition of lactic acid and propionic acid was not successful in terms of SA concentration.

\section{Acknowledgement}

This research was conducted within the framework of and in cooperation with PROGRESSIO Engineering Bureau Ltd., MÉL Biotech K+F Kft. and Budapest University of Technology and Economics.

\section{REFERENCES}

[1] Tonova, K.: State-of-the-art recovery of fermentative organic acids by ionic liquids: An overview Hung. J. Ind. Chem. 2017 45(2), 41-44 DOI: 10.1515/hjic-2017-0019

[2] Song, H.; Lee, S. Y.: Production of succinic acid by bacterial fermentation Enzyme Microb. Tech. 2006 39(3), 352-361 DOI: 10.1016/j.enzmictec.2005.11.043

[3] Sauer, M.; Porro, D.; Mattanovich, D.; Branduardi, P.: Microbial production of organic acids: Expanding the markets Trends Biotechnol. 2008 26(2), 100-108 DOI: 10.1016/j.tibtech.2007.11.006

[4] Zeikus, J. G.; Jain,-M. K.; Elankovan, P.: Biotechnology of succinic acid production and markets for derived industrial products Appl. Microbiol Biot. 1999 51(5), 545-552 DOI: 10.1007/s002530051431

[5] Liu, Y.-P.; Zheng, P.; Sun, Z.-H.; Ni, Y.; Dong, J.J.; Zhu, L.-L.: Economical succinic acid production from cane molasses by Actinobacillus succinogenes Bioresource Technol. 2008 99(6), 1736-1742 DOI: 10.1016/j.biortech.2007.03.044

[6] Mika, L.T.; Cséfalvay, E.; Németh, Á.: Catalytic conversion of carbohydrates to initial chemicals: Chemistry and sustainability Chem. Rev. 2018 118(2), 505-613 DOI: 10.1021/acs.chemrev.7b00395

[7] Li, X.; Jiang, S.; Pan, L.; Wei, Z.: Optimization for the bioconversion of succinic acid based on response surface methodology and back-propagation artificial neural network in: Wang, H; Low, K. S.; Wei, K.; Sun, J. (eds.): Fifth International Conference on Natural Computation 2009 3, 392398 (IEEE Computer Society, Los Alamitos, USA) ISBN: 978-0-7695-3736-8 DOI: 10.1109/ICNC.2009.20 